\title{
A Study on the Impact of Competition Intensity on Internationalization Degree and International Performance
}

\author{
Zhongwei $\mathrm{CaO}^{1, \mathrm{a} *}$, Jiang $\mathrm{Xu}^{2, \mathrm{~b}}$ and Zhiyuan $\mathrm{Liu}^{3, \mathrm{c}}$ \\ ${ }^{1}$ Department of Applied Mathematics, Jilin University of Finance and Economics, Changchun \\ 130117, P.R.China \\ ${ }^{2}$ School of Econimics and Management, Changchun University of Technology, Changchun 130000, \\ P.R.China \\ ${ }^{3}$ Department of Taxation, Jilin University of Finance and Economics, Changchun 130117, \\ P.R.China \\ aCaozw963@sina.com, bxujiang_1976@163.com, 'liuzhiyuan678@sina.com \\ * The corresponding author
}

Keywords: Competition intensity; Internationalization degree; International performance

\begin{abstract}
The advance of the economy globalization and integration of world economy puts a new challenge on the development of small and medium enterprises (SMEs). In order to actively cater to new science and technology revolution and related new technology application, SMEs looks and analyzes domestic and international market constantly to survive themselves in severe competition and realize the long-term development. To analyze the influence factors of internationalization degree and international performance, in this paper, we introduce the concept of competition intensity and analyze the impact of competition intensity on internationalization degree and international performance by analyzing documents. The results showed that there was a positive correlation between the competition intensity faced by SMEs and their internationalization performance, but there was a negative correlation between the competition intensity faced by SMEs and their internationalization degree.
\end{abstract}

\section{Introduction}

Fierce market competition has important effect on the development of SMEs and com-petition intensity is a part of the hostility of business environment. Hooley etc. once pointe-d out that competition intensity has important influence on the performance of multinational companies, which has influenced the internationalization process of enterprises to some ex-tent. And for SMEs especially, one of the key factors to determine whether the enterprises should go abroad to compete in the international markets is competition intensity. Enterprises should pay close attention to the changes of consumer demand and competitive environment of them in the market with higher competitive intensity (Welter et al., 2016)[1]. Day and Wensley pointed out that by monitoring the market to reduce market uncertainty, the survey on the competition intensity of business environment as well, which can help enterprises innovating products and taking measures as a strategic response to competitors. However, the SMEs are restricted by enterprise scale and resource endowment and their powerful domestic competitors is familiar with them, which has caused the damage of their market share and market performance. So, in order to open up market and achieve long-term development, enterprises should maintain market share and develop open up international markets to be globalization. Nowadays, most studies on the relationship between competition intensity and internationalization of SMEs, use competition intensity as other variables and adjusting variable between enterprise internationalization. And there is on studies using competition intensity as antecedents of enterprise internationalization. At the same time, we can nearly find studies on the relationship between competition intensity and international performance \& innovation. So, it is significative to use competition intensity as antecedents to research the influence of it on internationalization degree and international performance. 


\section{Related Concepts}

Competitive Intensity. Competitive intensity is the update frequency of competitive activities by scholar, including price war and frequency of sales promotion. They pointed out that new competition tricks or techniques, price competition and war of promoting sale is quite popular in the market. Other manufacturers will follow up or respond to the actions of competitors. All this will increase competition intensity.

In measuring the intensity of competition, Yang et al. (2009) [2]proposed a measure of competitive intensity, which consists of three measurement items:(1) The predictability of a business's key competitors' market activity; (2) The hostility of a business' s key competitors; (3) The breadth of a business's key competitors' activities. Yang et al. also argues that there are three main factors that determine competitive intensity: the number of competitors, size distribution of those competitors, the degree of the product difference.

International Performance. Semrau and Sigmund (2012) [3]has defined the international performance in detail. He believes that theinternational performance is the output from the international operation of enterprises. It specifically includes three parts. The first is international productivity and production efficiency, which is mainly reflected in the improvement of international capability. Second is international output performance, that is financial performance, such as international sales growth rate, international profit, etc. And third is non-financial indicators, mainly including foreign customer satisfaction\& recognition and international staff satisfaction. International performance is the final result of resource input in the process of internationalization of enterprises and result of transnational allocation of resources. Semrau and Sigmund (2012), from the perspective of entrepreneurship and institutional environment, evaluated the international performance, they believe that the international performance is the final output that enterprises continue to develop new products or create new enterprises to meet the environmental changes and foreign customers demand and it embodies the basic path to achieve the strategic goals and objectives of enterprise internationalization. In a word, this text thinks, international performance is the final output of resource input in the process of internationalization of enterprises. Its basic performance in the financial performance of the enterprise and is the basic index of the success of the enterprise internationalization.

Internationalization Degree. Reinholt et al. (2011) [4]summarizes the level of internationalization used by scholars in the past and classifies them into performance attributes, structural attributes, and attitude attributes. Performance attributes includes: the ratio of overseas sales to total sales, the intensity of $\mathrm{R} \& \mathrm{D}$ expenditure, intensity of advertising spending, the proportion of export sales to total sales and the proportion of overseas profit to total profit; Structural attributes include: the proportion of overseas assets to the total assets and the proportion of foreign subsidiaries in total number of subsidiaries; Attitude attributes includes: international experience ofhigh-level management and psychological dispersion of international operation. The former two are objective performance while the latter are subjective performance.

\section{Analysis of Effects}

In 1997, Grim and Smith proposed the relationship between competition interaction and competition intensity. They believe that the competition intensity determines how the enterprise will interact with other enterprises. Their research shows that lower competition intensity will make the behavior of enterprises not fully controlled by the environment, and enterprises will independently choose the market strategy. Although this strategy lacks rationality, it can enhance the performance of enterprises. In a highly competitive environment, the competition of an enterprise depends on the observation of actions between other competitors. In order to obtain competitive advantage and high performance, enterprises often face confrontational competition. At this time, enterprises will make rational decisions through competitive interaction to obtain external knowledge and resources actively, then make use of them to improve the basis of performance and to cope with fierce competition. Reinholt et al. (2011) has made a classification study of small and 
medium import and export enterprises in Holland. He found that resources and knowledge have potential value in the competitive market. SMEs must make use of information resources to respond quickly to the behavior of competitors, which is beneficial to the improvement of import and export performance.

The price school scholars, such as Mcdougall et al. (1994) analyze the relationship between competition intensity and enterprise performance (including international performance) from the point of view of price. In a competitive market, low price perception, that is, the initial perception of the consumer to the price of new products, can affect the competitive behavior of the enterprise. For SMEs, no matter how competitive the market is in the newly entered area, the utility of consumers will raise with the increase of the number of products and manufacturers, and then increase the cognition and purchase of the products and improve the performance of SMEs as long as enterprises can guarantee the sensitivity of consumers to their products' price perception and reduce the cost of consumers' search for their products. For SMEs, in the process of internationalization, in order to improve the performance of internationalization, they will choose competitive behavior rationally in the face of specific competitive areas.

The higher competitive strength has brought environmental uncertainty to some extent, that is, the unpredictability of the changes in the market environment, which reflects the complexity, unknown and unrest of the environment of enterprise, can be explained by the degree of market turbulence, the degree of technology turbulence and the degree of competitiveness level.

Among them, the degree of market turbulence is the degree and speed of changes in customers and their preferences, which makes it difficult for SMEs to figure out and grasp. The degree of technology turbulence is the degree and speed of change in technology and R \& D. The degree of competitiveness level is the degree of confrontation between the existing manufacturers in the market. Market-oriented researchers have proposed that when enterprises face fierce competition, they must pay attention to customer orientation, competitor orientation and Trans- inter departmental coordination, and build a trinity enterprise strategy for high intensity competition, but the internationalization process may be blocked at this time.

The turbulence in the market makes the supporters of reduce the supply of resources when they perceive the adverse environment, at the same time, SMEs will also cut the input of international resources to some extent, and reduce the internationalization process and level, so as to reduce the uncertainty of resource returns. And the degree of technology turbulence makes the evaluation of technology made by SMEs exceed expectation and the enterprise can not carry out the international operation according to the established technical line, which will also reduce the level of internationalization. The fierce competition can not ensure the short-term income of SMEs. For SMEs which are more concerned about short-term performance, the performance of their international operation is difficult to be guaranteed because of fierce competition, and their assets will be eroded because of the fierce competition from foreign markets. SMEs will consider the process of internationalization, at this point, they will take a very cautious attitude.

The purpose of customer orientation is to create superior value for customers. This requires the SMEs in the process of internationalization to fully understand the target customer group and to create the superior value for them, but the higher competition intensity makes it more difficult for SMEs to create the superior value for the customers. The competitor orientation requires SMEs to understand the short-term strength and weakness between the current and potential competitors in the international market, as well as a long-term capability and sex strategy. However, because Gillette's competition and technology turulence are beyond the expectations of SMEs, it is difficult to capture and obtain related information from foreign competitors, which will force SMEs to slow down, reduce their levels to ensure the value of investment assets in the process of internationalization.

Inter departmental coordination in SMEs is adjustment mainly based on the changes in the value demand of the purchasing groups on the target market, that is, interdepartmental integration of enterprise resources. Creating superior value for the target customer group is the basic goal of SMEs in seeking the niche market opportunities. However, the market turbulence, the fierce 
competition and the expected change of technology make the effective coordination within the SMEs difficult to continue and their international efficiency to be lower. For this reason, SMEs will carefully choose the path of internationalization.

Therefore, there was a negative correlation between the competition intensity faced by SMEs and their internationalization degree

\section{Research Inspiration}

In previous studies on internationalization, most studies regard competition intensity as a moderator between two variables to explore its impact on the relationship between variables. Only a few scholars have analyzed the direct effect of competitive intensity on international performance and internationalization degree from a qualitative perspective. It is the first time to study the impact of competition intensity on international performance and internationalization degree, and find that it has a positive impact on the former, but it has a negative impact on the latter.

The higher competition intensity of SMEs, the higher their international performance will be. This result supports the previous hypothesis. This shows that for the internationalization of SMEs, the higher competition intensity of the market, the more conducive to the development and performance improvement of SMEs. In order to survive in the overseas market, it makes the SMEs respond to the market demand and personal preference with the minimum price guarantee, which, to a certain extent, increases the consumer's awareness of the new products, thus increasing the price assurance of the local consumers, setting up the image and prestige of the enterprise in the local market and ensuring the performance of the enterprise in the overseas market. Some scholars believe that in the international market, the price guarantee in the competitive industries will enable consumers to search for the price. If the SMEs can hold this special opportunity, they can turn the fierce market competition into the driving force of the enterprise development, keep their footing in the overseas market and lay the foundation for the quality performance. It is believed that if SMEs want to survive in the competitive overseas market, the first condition is to control the cost, lower the price, and make the foreign consumers feel that their products have lower prices and better quality. Only in this way can we overcome a series of unfavorable conditions such as fierce competition, abundant products and numerous manufacturers, so as to ensure that the internationalized performance of enterprises is not eroded.

\section{Acknowledgement}

The authors would like to thank NSFC (No. 11701209), the Project of Science and Technology Development Plan for Jilin Province (No.20160520110JH) and Science and Technology Research Project of Jilin Provincial Department of Education of China (JJKH20180462KJ,2015162) for financially supporting this research.

\section{References}

[1] Welter C, Mauer R, Wuebker R J. Bridging behavioral models and theoretical concepts: effectuation and bricolage in the opportunity creation framework. Strategic Entrepreneurship Journal, 10(2006):5-20.

[2] Yang Y, Narayanan V K, Zahra S. Developing the selection and valuation capabilities through learning: The case of corporate venture capital. Journal of Business Venturing, 24(2009):261-273.

[3] Semrau T, Sigmund S. Networking ability and the financial performance of new ventures: A mediation analysis among younger and more mature firms. Strategic Entrepreneurship Journal, 6(2012)335-354.

[4] Reinholt M, Pedersen T, Foss N J. Why a central network position isn't enough: The role of motivation and ability for knowledge sharing in employee networks.. Academy of Management Journal, 54(2011):1277-1297. 
[5] Mcdougall P P, Covin J G, Jr R B R, et al. The effects of industry growth and strategic breadth on new venture performance and strategy content. Strategic Management Journal, 15(1994)537-554.

[6] Peng L, Fang W. Heterogeneity of Inferring Reputation of Cooperative Behaviors for the Prisoners' Dilemma Game [J]. Physica A: Statistical Mechanics and its Applications, 2015, 433: 367-378. 